\title{
Examining the Present and Future Integrated Role of Artificial Intelligence in the Business: A Survey Study on Corporate Sector
}

\author{
Awais Khan Jumani ${ }^{1 *}$, Asif Ali Laghari², Kamlesh Narwani1,3, Shibin David ${ }^{4}$ \\ ${ }^{1}$ Faculty of Science and Technology, ILMA University, Karachi, Pakistan \\ ${ }^{2}$ Department of Computer Science, Sindh Madressatul Islam University, Karachi, Pakistan \\ ${ }^{3}$ School of Electronic Information and Communications, Huazhong University of Science and Technology (HUST), Wuhan, \\ China \\ ${ }^{4}$ Karunya Institute of Technology and Sciences, Coimbatore, India \\ Email: *awaisjumani@yahoo.com
}

How to cite this paper: Jumani, A.K. Laghari, A.A., Narwani, K. and David, S. (2021) Examining the Present and Future Integrated Role of Artificial Intelligence in the Business: A Survey Study on Corporate Sector. Journal of Computer and Communications, 9, 80-90. https://doi.org/10.4236/jcc.2021.91008

Received: January 11, 2021

Accepted: January 26, 2021

Published: January 29, 2021

\begin{abstract}
In the fast-moving world, it is noticed that every industry is developing gradually, but recently it is identified that the use of AI has become the talk of own. Therefore, this study is focused on gathering data regarding the AI on how it has transformed the entire world's corporate sector. The essential application $\mathrm{AI}$ in the business world helps the business to perform better in the corporate sector. In this paper, the critical role of artificial intelligence is to grow business in different sectors and also address its ethical and unethical issues. The paper has all the initial background and comprehensive literature regarding AI and machine learning. It is discovered how the technological world has been striving to take their business on to new heights, which requires updated technological changes in internal business activities. Companies can now effortlessly interact with their customers in making their application accessible for the end-users through implementing AI and machine learning. Companies are getting higher profitability and enhancing their performance and achieving economic advantages by integrated AI. Moreover, their technological developments will take human jobs in the future, so, it is suggested that humans should work on their skills and competencies so that they can deal with unemployment.
\end{abstract}

\section{Keywords}

Artificial Intelligence, Machine Learning, Functions of AI, Use of AI in Business, Cooperate Sector 


\section{Introduction}

In the modern environment, $\mathrm{AI}$ and machine learning have become the most popular technological advancement in today's world, living in a third world country like Pakistan, but not utilizing the technologies properly in our business sector. As many of the technologies have been introduced day by day to reduce the workload and make efficient work. However, in Pakistan, many of the companies not adopt new technologies due to a lack of awareness and training. AI has been taking place since last year's gradually, and it needs to take some vital action towards this because, in the future, everything will be based on AI [1]. This kind of research will help in business so that they can have enough knowledge regarding AI. If it compares with companies and the international business, it comes to know companies do not have enough knowledge and information regarding AI. International businesses are growing just, because they have adopted $\mathrm{AI}$ in the past.

Nevertheless, in Pakistan, the companies are still fighting with traditional issues, because they do not have to implement machine learning yet. Although it has a massive market comparing with internationally, the customer's satisfaction is high. They have implemented and transformed their business with these applications. Therefore, this study has to be taken place for those companies who want to adopt AI due to a lack of knowledge they are unable to do so. These AI topics are very sensitive, so it must be discussed widely; if not, then it will not be able to compete with the new challenges in the future. If significant changes and issues are not taken place so, it will be a disaster for our business and corporate sector. The main contribution of this study is to highlight the central issue of AI on how our business goes far away from AI. In this research, artificial intelligence and machine learning have been explained very well. The introductions and the uses of both the application have been identified and describe well. In today's world, whereas businesses are running on fully equipped technological advancement recently, the use of AI has become the talk of the town. Companies are using the application and features of $\mathrm{AI}$ and machine learning to get better processes and procedures inside and outside of the company. With the use of these systems, the corporate sector has been growing, its customers and clients with the help of identifying needs and wants. The study has explained the present uses of AI and further how it can use in the future as well.

This study has covered all the ethical and unethical use of AI in the business. Every technological advancement has its pros and cons; therefore, AI also has its cons. Some companies use AI to manipulate their data the statistics with the help of the algorithm. On the other hand, the companies use it ethically too. In this research, it is clear to know how the companies are manipulating data and misusing it to get profit and benefit. This research has described how a business can grow and make them more powerful with the use of AI and machine learning in this fast-moving phase. The study has discovered multiple uses of AI in the company. Companies can use AI to retain all the data, not just for their cus- 
tomers; they can retain their data for their employees who are working or ever worked in a company. Different examples have been discussed and highlighted in this research. With just implementing AI, the companies can make their system more systematic than ever. They are no longer and do not have to depend on human power instead, they can make their work easy and automated with the use of artificial intelligence and machine learning. This research has been developed through collected second-hand data, which refers to previous researches that have been done in the past. This study has also gathered data of leading companies related to AI; however, some other companies who are at the initial stage of implementing their data could be collected. The type of research for this study has been selected exploratory; therefore, other types can be considered, such as qualitative or quantitative.

The paper organization depends upon the following 7 sections. Section 1 depends upon the overall introduction, and section 2 shows the significance of the study. Section 3 shows the literature review, and section 4 depends upon methodology. Section 5 is based on the results and discussions. Section 6 depends upon overall conclusion and in last section 7 depends upon the recommendations.

\subsection{Artificial Intelligence}

In the world of digitalization, it has been experiencing drastic changes since recent past years discovered by communication and information technology, machine learning, robotics, and the most important artificial intelligence highlighted [2]. According to [3] AI, which means artificial intelligence is defined as a computer-based system that is formed to assist and analyze the system that can be called intelligence. This can also be explained as a system designed by humans and its intelligence is transformed as a machine. The aim of this research to discover what are some prominent opinions in reality, what would be the greatest professionals presently allocate artificial intelligence in the specific time, how many risks they analyze with this advancement, and lastly, how quickly they examine? [4]. Artificial intelligence has two primary kinds, such as powerful and weak, along with logic, sensory, and mindfulness. It can perform in multiple domains instead of a specific one. The word called as artificial narrow intelligence belongs to machines that have powerful intelligence in a unique domain. The artificial intelligence application utilizes technologies that contain natural processing language, machine learning, speech recognition, computer vision, and robotics. All of this technological advancement gives benefits and opportunities to businesses. Companies can collect and retain data, and even the data can be recovered, which was not possible when this kind of application does not introduce and implements [5] [6].

\subsection{Machine Learning}

The main element of $\mathrm{AI}$ is machine learning, which enables all systems of computers to study by experience, examples, and data directly. Once it is enabled to 
the computer to do particular procedures smartly, this machine learning systematic procedure can take out the most valuable data by identifying them instead of following the traditional programmed process. An increasing number of data availability has promoted the system of machine learning to qualify on massive examples of the pool when building and supporting the processing of computer power to the complexity of the system. In this system of machine learning, there are advanced algorithms that have to empower this system. The result of these systems has become exceptionally tremendous under the supervision of humans, and at some places, these systems worked far better than human tasks. In the corporate sectors, many companies are approaching machine learning daily, such as image recognition system. In this era, machine learning is being utilized in many ways and applications, and it is also an important idea of intelligent systems [7]. This study has presented the initial process and implementation of artificial intelligence and machine learning that help to develop business. It started with an introduction, and then it went further [8].

\section{Supervised and Unsupervised Machine Learning}

Further stated [9] that machine learning can be categorized into two types. One category is supervised learning and the second one is unsupervised learning. The second unsupervised leaning tends to give results as in conclusion from the multiple sets of data that contain the input of the data with no responses labeled. It can be said that in this category, the expected result is not presented. The first category, which is supervised learning, tends to identify the relationship among the attributes of two variables that input as dependent or independent variables.

\subsection{Functions of Artificial Intelligence and Machine Learning Business}

A study conducted by [10] states that one of the rare artificial intelligence applications in the business is voice search, ad targeting, productiveness analysis, content creation, dynamic pricing, and lead scoring. Through the use of these listed applications of AI, businesses can identify their audiences and potential buyer's movements and also analyze their behavior from time to time and can attain their business goals through future forecasting as well. With the help of artificial intelligence, the business can make strong relationships with customers and businesses. Many companies are now utilizing artificial intelligence for different purposes, such as in email and SMS marketing, to run the campaigns along with the improved connections and alteration to its users and the clients. One of the best uses of AI until now is digital advertising that is most successfully worked. The best use of AI and machine learning can be explained through two best examples, like Google and Facebook. These two companies are using AI applications to identify their audience's demographics and their interest in studying and recognize the best-suited audience for different brands. The predictive analysis tends to utilize the statistics algorithm, data, and also machine learning tactics with the focus to search future results based on data and history. In mul- 
tiple domains, the machine learning application has been utilizing to perform different tasks. There is an essential application that contains customer profiling, medical diagnosis, market segmentation, fraud detection, target marketing, credit risk analysis, and retail management [11]. Technology like AI and machine learning can bring profitable change for the brands and companies by giving them accurate data timely [12].

\subsection{Unethical Use and Risks of AI in Business}

Scholars believe that two important aspects of artificial intelligence. One is to understand the AI higher risks, and the second most important aspect of AI can be automated to perform something demoralizing. A program can kill a system. These can give undesirable results to the company and create high risk. This type of technological advancement may risk the entire data of the company by just manipulating the codes of AI application. Experts are also bothered by this aspect that when AI application is generated to perform something outstanding beyond the human expectation by unethical procedures. Such as, if the application algorithm has set to let a person at his desire destination like airport speedily, it might happen that the application will not consider the safety aspect of the person. The above two aspects have given an outline of the higher risks for the initial process of AI [13]. According [3] stated that Old business tactics have been revitalizing as modern business endorsed by artificial intelligence.

\section{Significance of the Study}

This research would be essential for those companies, brands, marketing teams, businesses, and corporate sectors that are capable of implementing advanced technology. However, due to the lack of knowledge, they are unable to do so. Particularly in Pakistan, many companies are still not aware of the use of Artificial Intelligence and Machine learning in business. These two focal technological advancements can make the business grow. This research will be helpful for marketers who invest billions in the advertisements; however, still unsuccessful in achieving their target audience. This research has presented some previous innovative business models that can help the corporate sector to improve and make their system efficient enough to perform the tasks and can give a better result based on statistics developed by AI.

\section{Literature Review}

\subsection{AI Business Model Use by Leading Companies}

A study conducted by [14] numerous leading companies like Alibaba, Google, Uber, Amazon, and UPS, along with other famous companies, have integrated their fundamental business models and improved their competitive advantage by utilizing AI efficiently. Topmost officials need to promote and innovation and entrepreneurial mindset to achieve their goals and reach their target by using $\mathrm{Al}$ in the business. The recent study on business model innovation, particu- 
larly stresses on outside backgrounds that might force a business to indulge in business model innovation. Top famous companies that are high in the use of technology, as mentioned above, they have declared innovative growth depends on deep learning, such as image recognition or speech recognition. Amazon, Spotify, and Netflix are using machine learning and its algorithm to develop customer-made approvals. One of the branches AI, called neutral AI, is effective in working amazingly to define issues like perception and recognition with several data that is labeled. Presently, at this stage, the development process of neutral AI can be argued as this is way beyond human thinking and reasoning, and it needs so much data that is labeled.

\subsection{Major Trends of AI Technology in Business}

AI application contains recognizing the machines and the use of language. Concepts form abstractions and to resolve complex problems. The vast and rising data accessible nowadays and the stable developments of computational influence and systems have produced various AI applications through numerous varied businesses. Although classifications and ideas of AI differ with the objectives and area, the key specifications of AI are copying human reasoning purposes, principally knowledge, and problematic resolving. It is famous that the idea projected in 1956 has been measured still related to the present AI investigation [15]. According to [16] stated in their studies, the basic idea to retain how can companies retain and maintain their position in the market through the innovative business model is being discussed widely presently. This stress might likewise rise by high-tech interruptions. Investigators claim that this procedure of business model innovation has been disposed of and influence by their atmosphere stated [17]. Whereas the earlier studies emphasize on outside factors which might stress business to indulge in the innovative business models. There is one research that was recently conducted that how companies can effectively use technological advancements to enhance their business models and improve their business system through the use of AI applications [18]. The human who will have a bright future in their career field will be from the IT, manufacturing, graduates who have command on technology and will be able to resolve all the issues related to technological advancement [19].

\subsection{Current Technological Development in AI}

The reference of the research done by [14] examined that scholars approve that AI is in its initial days. There is a lot of development left to reach and to be done in the future. Effective use of AI allows reasoning capabilities and scaling learning through more significant applications in this situation, Yoshua Bengio entitled AI previous studies to have to broader the ability for cognitive, causality, learning, and discovering the world for learning and attaining knowledge. Business model signifies an action structure or a group of co-dependent actions covering the company's limitations and business model innovation is well-defined 
as an essential alteration in the business's Processes and worth formation, characteristic resulting in development in a business presentation. AI has been promoting business model innovation crossways businesses counting machinery/media, customer products, monetary services, well-being care, industrialized, energy, and community sector. Over 3000 business administrative interviewed and revealed that $84 \%$ of people think AI would allow the business to attain or retain the competitive market advantage, and $75 \%$ believe that AI also would enable the companies to make and add new business and new ventures with the existing business models [20] [21]. To obtain such human-machine business, human involvement is debatably unavoidable. Consequently, the opportunity of taking a completely AI-based structural decision structure is thoughtless [22]. As discussed earlier regarding the risks of AI, those can be handled well. There is a significant risk of AI that affects human jobs and can cause the result to loss of a job. As per the article published in the US, today quoted that technology like AI can ruin 73 million people's jobs in the US until 2030, on the other hand. The article more emphasis that many jobs can be affected, but the fundamental tasks only will be performed by the human. Therefore, employees have to improve their skills. So they can efficiently do all the tasks and can contribute to economic growth. The company can get a profit at the end of the year [6]. Many employees are managing their job with an unpleasant environment are at low risk. The industry will change due to AI; many will get a job, and some will be laid off by just the implementation and adaptation of artificial intelligence. Furthermore, business systems and processes have highlighted and how AI and machine learning have been transforming the digital world by its efficient and smart innovations and impacting the whole business world and also economy discussed [23].

\section{Methodology}

The research method is used in this research is secondary data analysis. The core idea to do this research is to recognize the facts about machine learning and AI. As in this study, the primary source to collect data is to research the previous study; therefore, it has selected an experimental research method. This study has a detailed analysis of explaining AI and machine learning in different areas of the business. This research also includes the functions and models of AI that are being used by the companies of the corporate sector throughout the world. Therefore, it is necessary to discover about Pakistan's corporate sector to research where it is standing. In Pakistan, some companies are still striving against their day to day challenges. The Pakistan sector is still behind comparing with internationally. Multiple types of research have been added in this research to support the facts and statistics. After searching many types of research, it has to review their paper thoroughly and get the data from them. For improving the quality of this research it has taken data from previous work which has been done on AI into the business. As well as, some of the questionnaire has been dis- 
tributed physically in different business sectors and collected data step by step. So, this research reaches on some significant results which are discussed in the result section.

\section{Result and Discussion}

According to the data and scholar's opinion, it has gathered the facts that AI has a significant impact on different aspects of the business. As shown in Figure 1, this data can conclude that $\mathrm{AI}$ is helping businesses to grow as years have been passing.

In Figure 2, a worldwide online survey has conducted, and data has been gathered through questionnaire form different employees those are employed in different sectors.

\section{Conclusions}

The study has aimed to go through within the different articles researches and

AI and Its Future Impact

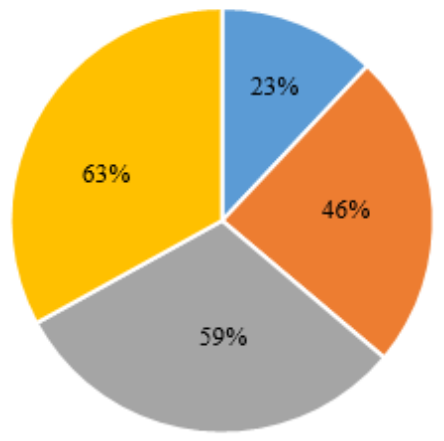

- AI negetive impact on business = AI impact on jobs

= AI impact in human lives $\quad$ " AI and complex peoblem solving

Figure 1. AI and its future impact.

Using $\mathrm{AI}$ in Business

Last Three Years Data

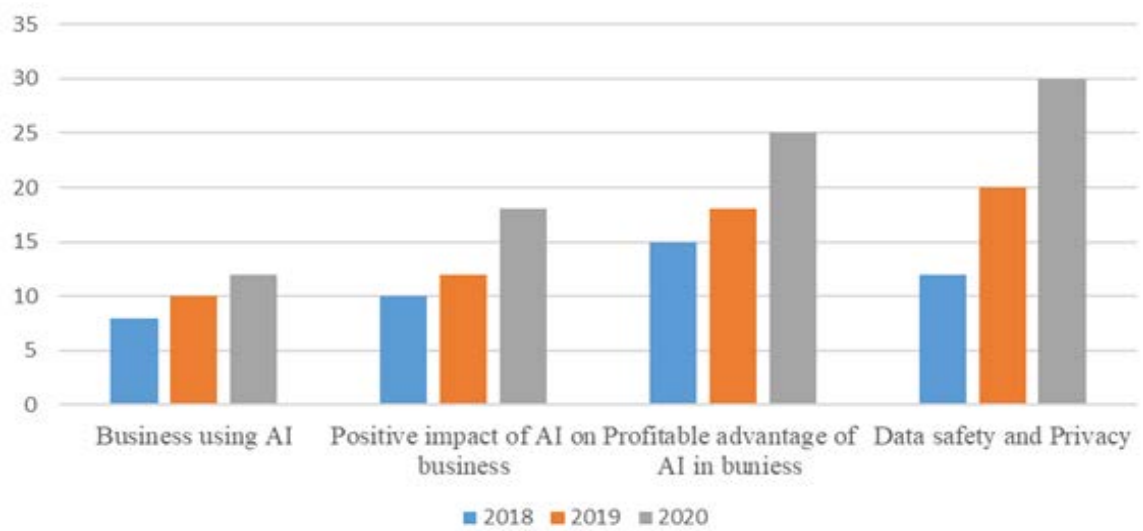

Figure 2. Using AI in Business. 
online browsing. Due to the research type, many aspects and allegations have not been discussed in-depth but can be suggested for further future research. Therefore, these many references have been cited from the current issues from scientific generals and development. Everything related to technology has several benefits and risks too. The same happens in the AI process when businesses start utilizing the application. AI application gives numerous advantages, which even human is unknown to it. In the coming time, it will experience AI will bring a drastic change in the field of teaching and training, solving real-time problems, predictive analysis, empowering the disabled, custom textbooks, and dynamic scheduling. It has concluded that AI advancement has not only to help in collecting the customer's insights for the business provided the complete data.

Additionally, it is emphasized and suggested that the government must have to plan and be prepared to adopt like innovative ideas that are more automated and can work fast like AI, and also discussed that human could lose their jobs, and the unemployment rate will be high in the future due to the change of AI. This study also elaborated that AI can assist as a more operational director for the upcoming instead of a concern along with great intelligent machines that can duplicate each feature of human brainpower and finally switch them in work. Hence proved with the help of earlier studies, it is identified that the battle between humans and machines has become more argued and beneficial at the same time. Machines are making the human task more comfortable and convenient for human and let the human to focus on more efficient work. Machines have made the human workload less and now human has more systematic data with privacy.

\section{Conflicts of Interest}

The authors declare no conflicts of interest regarding the publication of this paper.

\section{References}

[1] Siddiqui, M.F., Siddique, W.A., Ahmedh, M. and Jumani, A.K. (2020) Face Detection and Recognition System for Enhancing Security Measures Using Artificial Intelligence System. Indian Journal of Science and Technology, 13, 1057-1064. https://doi.org/10.17485/ijst/2020/v013i09/149298

[2] Gupta, S., Keen, M., Shah, A., Verdier, G. and Walutowy, M.F. (Eds.) (2017) Digital Revolutions in Public Finance. International Monetary Fund, Washington DC.

[3] Shahid, M.Z. and Li, G. (2019) Impact of Artificial Intelligence in Marketing: A Perspective of Marketing Professionals of Pakistan. Global Journal of Management and Business Research.

[4] Bostrom, N. (2016) Fundamental Issues of Artificial Intelligence (Vol. 376). V. C. Müller (Ed.), Springer, Berlin.

[5] Jarrahi, M.H. (2018) Artificial Intelligence and the Future of Work: Human-AI Symbiosis in Organizational Decision Making. Business Horizons, 61, 577-586. https://doi.org/10.1016/j.bushor.2018.03.007 
[6] Geisel, A. (2018) The Current and Future Impact of Artificial Intelligence on Business. International Journal of Scientific \& Technology Research, 7, 116-122.

[7] Sharma, D. and Kumar, N. (2017) A Review on Machine Learning Algorithms, Tasks and Applications. International Journal of Advanced Research in Computer Engineering \& Technology (IJARCET), 6, No. 10.

[8] Aghion, P., Jones, B.F. and Jones, C.I. (2017) Artificial Intelligence and Economic Growth (No. w23928). National Bureau of Economic Research. https://doi.org/10.3386/w23928

[9] Soofi, A.A. and Awan, A. (2017) Classification Techniques in Machine Learning: Applications and Issues. Journal of Basic and Applied Sciences, 13, 459-465. https://doi.org/10.6000/1927-5129.2017.13.76

[10] Mitić, V. (2019) Benefits of Artificial Intelligence and Machine Learning in Marketing. In Sinteza 2019-International Scientific Conference on Information Technology and Data Related Research (pp. 472-477). Singidunum University.

[11] Tzanis, G., Katakis, I., Partalas, I. and Vlahavas, I. (2006) Modern Applications of Machine Learning. In Proceedings of the 1 st Annual SEERC Doctoral Student Conference-DSC (Vol. 1, No. 1, pp. 1-10).

[12] Milgrom, P.R. and Tadelis, S. (2018) How Artificial Intelligence and Machine Learning Can Impact Market Design (No. w24282). National Bureau of Economic Research. https://doi.org/10.3386/w24282

[13] Hintze, A. (2016) Understanding the Four Types of AI, from Reactive Robots to Self-Aware Beings. The Conversation.

https://theconversation.com/understanding-the-four-types-of-ai-from-reactive-rob ots-to-self-aware-beings-67616

[14] Lee, J., Suh, T., Roy, D. and Baucus, M. (2019) Emerging Technology and Business Model Innovation: The Case of Artificial Intelligence. Journal of Open Innovation: Technology, Market, and Complexity, 5, 44. https://doi.org/10.3390/joitmc5030044

[15] Sosna, M., Trevinyo-Rodríguez, R.N. and Velamuri, S.R. (2010) Business Model Innovation through Trial-and-Error Learning: The Naturhouse Case. Long Range Planning, 43, 383-407. https://doi.org/10.1016/j.lrp.2010.02.003

[16] Wirtz, B.W., Schilke, O. and Ullrich, S. (2010) Strategic Development of Business Models: Implications of the Web 2.0 for Creating Value on the Internet. Long Range Planning, 43, 272-290. https://doi.org/10.1016/j.lrp.2010.01.005

[17] Chesbrough, H. (2010) Business Model Innovation: Opportunities and Barriers. Long Range Planning, 43, 354-363. https://doi.org/10.1016/j.lrp.2009.07.010

[18] Velu, C. (2015) Business Model Innovation and Third-Party Alliance on the Survival of New Firms. Technovation, 35, 1-11. https://doi.org/10.1016/j.technovation.2014.09.007

[19] Hirst, T. (2014) Does Technological Innovation Increase Unemployment? In The World Economic Forum Blog. https://agenda.weforum.org/2014/11/does-technological-innovation-increaseunemp loyment

[20] Gassmann, O., Frankenberger, K. and Sauer, R. (2017) A Primer on Theoretically Exploring the Field of Business Model Innovation.

https://doi.org/10.1007/978-3-319-41144-6

[21] Lindgardt, Z., Reeves, M., Stalk, G. and Deimler, M.S. (2009) Business Model Innovation. When the Game Gets Tough, Change the Game, The Boston Consulting Group, Boston, MA. 
[22] Davenport, T. (2016) Rise of the Strategy Machines. MIT Sloan Management Review.

https://scholar.google.com/scholar_lookup?title=Rise\%20of\%20the\%20strategy\%20 machines\&author=T.H.\%20Davenport\&publication_year=2016\&pages=13-16

[23] Dirican, C. (2015) The Impacts of Robotics, Artificial Intelligence on Business and Economics. Procedia-Social and Behavioral Sciences, 195, 564-573.

https://doi.org/10.1016/j.sbspro.2015.06.134 